\title{
Planejamento de ensino para jovens com síndrome de Down a partir da Escala de Intensidade de Apoio (SIS)
}

Teaching planning for young people with Down syndrome using the Supports Intensity Scale (SIS)

Planificación de la enseñanza para jóvenes con síndrome de Down utilizando la escala de intensidad de apoyo (SIS)

Polyane Gabrielle de Freitas

Doutoranda na Universidade Federal de São Carlos, São Carlos, São Paulo, Brasil. polyanef123@gmail.com

ORCID - https://orcid.org/0000-0002-7849-4093

Márcia Duarte Galvani

Professora doutora na Universidade Federal de São Carlos, São Carlos, São Paulo, Brasil. marciaduar@yahoo.com.br

ORCID - https://orcid.org/0000-0003-1092-746X

Recebido em 15 maio 2020

Aprovado em 28 de setembro de 2020

Publicado em 26 de outubro de 2020

\section{RESUMO}

O estudo teve como objetivo avaliar a intensidade de apoio nos comportamentos adaptativos de jovens com síndrome de Down e aplicar em colaboração com o professor, um planejamento de ensino a partir da necessidade de apoio. O estudo seguiu a abordagem qualitativa descritiva pautada na investigação ação. Foram participantes uma professora de Educação Especial, dois jovens com síndrome de Down e seus respectivos pais. A coleta de dados foi realizada em uma Associação de Pais e Amigos dos Excepcionais, de um município de médio porte, localizado no interior do estado de São Paulo e na residência dos participantes. Os instrumentos utilizados foram a Escala de Intensidade de Apoio - SIS, desenvolvida pela Associação Americana de Deficiência Intelectual e Desenvolvimento (AAIDD), tendo como respondente os pais dos jovens com síndrome de Down e um roteiro para elaboração do planejamento de ensino. Os dados foram organizados em duas categorias de acordo com os temas abordados: necessidade de apoio nos comportamentos adaptativos dos jovens com síndrome de Down e elaboração e aplicação do planejamento de ensino a partir da necessidade de apoio. Como resultados, verificou-se que a área em que os jovens com síndrome de Down necessitavam de maior apoio era em aprendizagem ao longo da vida e após o planejamento de ensino, houveram modificações positivas no envolvimento nas atividades propostas, interação com colegas, professora e pesquisadora. Espera-se que este estudo sirva como exemplo de boas práticas, assim como de indicação para o uso da Escala SIS como ferramenta para o planejamento de ensino.

Palavras-chave: Educação Especial; planejamento de ensino; comportamento adaptativo. 
http://dx.doi.org/10.5902/1984686X44225

\section{ABSTRACT}

The study aimed to assess the intensity of support in the adaptive resources of young people with Down syndrome and to apply, in collaboration with the teacher, a teaching plan based on the need for support. The study followed a descriptive qualitative approach based on the investigation action. A Special Education teacher and two young people with Down syndrome and their respective parents participated. Data collection was carried out in an Association of Parents and Friends of the Exceptional, a medium-sized municipality located in the interior of the state of São Paulo and in the residence of participants. The instruments used were the Support Intensity Scale - SIS, developed by American Association on Intellectual and Developmental Disabilities (AAIDD), having as respondent the parents of young people with Down syndrome and a script for the preparation of teaching planning. The data were organized into two categories according to the topics covered: the need for support in the adaptive applications of young people with Down syndrome and the application and application of teaching planning based on the need for support. As a result, it was found that the area in which young people with Down syndrome need more support was in lifelong learning and after teaching planning, some positive changes in the use of activities, interaction with colleagues, teachers and researcher. It is hoped that this study will serve as an example of good practice, as an indication of the use of the SIS Scale as a teaching planning tool.

Keywords: Special Education; teaching planning; adaptive behavior.

\section{RESUMEN}

El estudio tuvo como objetivo evaluar la intensidad del apoyo en los comportamientos adaptativos de los jóvenes con síndrome de Down y aplicar, en colaboración con el maestro, un plan de enseñanza basado en la necesidad de apoyo. El estudio siguió el enfoque cualitativo descriptivo basado en la investigación de acción. Participaron una maestra de Educación Especial y dos jóvenes con síndrome de Down y sus respectivos padres. La recolección de datos se llevó a cabo en una Asociación de Padres y Amigos de los Excepcionales, de un municipio de tamaño mediano, ubicado en el interior del estado de São Paulo y en la residencia de los participantes. Los instrumentos utilizados fueron la Escala de intensidad de soporte - SIS, desarrollado por la Asociación Estadounidense para la Discapacidad Intelectual y el Desarrollo (AAIDD), teniendo como encuestados a los padres de jóvenes con síndrome de Down y un guión para la preparación de la planificación de la enseñanza. Los datos se organizaron en dos categorías según los temas tratados: la necesidad de apoyo en los comportamientos adaptativos de los jóvenes con síndrome de Down y el desarrollo y la aplicación de la planificación de la enseñanza basada en la necesidad de apoyo. Como resultado, se descubrió que el área en la que los jóvenes con síndrome de Down necesitaban más apoyo era el aprendizaje permanente y después de la planificación de la enseñanza, hubo cambios positivos en la participación en las actividades propuestas, la interacción con colegas, maestros y investigador. Se espera que este estudio sirva como un ejemplo de buenas prácticas, así como una indicación para el uso de la Escala SIS como una herramienta para la planificación de la enseñanza.

Palabras clave: Educación Especial; planificación de la enseñanza; comportamiento adaptativo. 
http://dx.doi.org/10.5902/1984686X44225

\section{Introdução}

A síndrome de Down-21 também conhecida por trissomia do 21 é uma alteração cromossômica, na qual há a presença de um cromossomo 21 extra. Sua primeira descrição foi feita por John Langdon Down, em 1866, na qual era utilizada a terminologia "idiotia mongólica" para referir os sujeitos que apresentavam as características da síndrome (BRASIL, 2013).

A síndrome pode ser diagnosticada após o nascimento, devido à presença do fenótipo característico da síndrome de Down. Entretanto, essas alterações fenotípicas devem ser consideradas em conjunto para esclarecer a suspeita do diagnóstico (BRASIL 2013).

As Diretrizes de Atenção à Pessoa com Síndrome de Down destacam que, além das características físicas, algumas pessoas com síndrome de Down podem vir a ter problemas, tais como: infecções, cardiopatias, problemas respiratórios, problemas na visão, problemas digestivos e auditivos (BRASIL, 2013). Ainda, a pessoa com síndrome de Down tem como caraterística a deficiência intelectual, antes denominada deficiência/retardo mental (KOZMA, 2007; ALMEIDA, 2012).

O Manual Diagnóstico e Estatístico de Transtornos Mentais DSM-V (APA, 2014) define a deficiência intelectual como um transtorno iniciado no período do desenvolvimento e marcado por déficits funcionais, tanto intelectuais quanto adaptativos, nos domínios conceitual, social e prático, podendo ser classificado em quatro níveis, de acordo com a gravidade: leve, moderada, grave e profunda. Em concordância com isso, considera-se três critérios para realizar o diagnóstico da deficiência intelectual: A. Déficits em funções intelectuais; B. Déficits em funções adaptativas; C. Início dos déficits intelectuais e adaptativos durante o período do desenvolvimento (APA, 2014).

Durante longo tempo, o funcionamento intelectual foi medido por meio do Quociente de Inteligência (Teste de QI), que avalia o indivíduo nos seguintes aspectos: raciocínio, conceituação e pensamento, bem como classifica a deficiência em leve, moderada, severa e profunda (KOZMA, 2007; ALMEIDA, 2012). Contudo, a deficiência intelectual não deve ser classificada somente por testes de QI, mas também devem ser aplicados outros testes cuja prioridade seja o comportamento adaptativo (ALMEIDA, 2012).

Ferreira e Munster (2015) promoveram um estudo com o intuito de analisar os métodos de avaliação do comportamento adaptativo das pessoas com deficiência intelectual. Utilizando os descritores adaptative behavior AND intellectual disability, foram encontrados 89 estudos, dentre estes, 60 tratavam da avaliação do comportamento 
http://dx.doi.org/10.5902/1984686X44225

adaptativo de tais sujeitos. Os resultados apresentaram três formas de avaliação: formas não padronizadas e não validadas, que correspondem à $20 \%$ dos casos (observação direta e indireta, entrevista e cenário comportamental), instrumentos de avaliação validados e padronizados com $70 \%$ e combinados com $10 \%$, ou seja, instrumentos padronizados e não padronizados.

No que se refere aos instrumentos padronizados, foram localizados 11 a saber: Vineland Adaptative Behavior Scales, Adaptative Behavior Scales, Adaptative Behavior System, Child Behavior Checklist, Matson Evaluation of Social Skills for Individuals with Severe Retardation, Quebec Adaptative Behavior Scale, Community Self Sufficiency Test, Inventory for Client and Agency Planning, Scales of Independent Behavior-Revised; Assessment Evalution Programming System for infants and children e Diagnostic Adaptive Behavior Scale. Dos instrumentos encontrados, somente o Vineland Adaptative Behavior Scales está adaptado no contexto brasileiro (FERREIRA; MUNSTER, 2015).

No contexto brasileiro, tem-se registro de um instrumento que mede o funcionamento adaptativo, porém encontra-se em fase de validação. $O$ instrumento foi traduzido e adaptado pela Universidade Federal de São Carlos e é conhecido como Escala de Intensidade de Apoio (Supports Intensity Scale - SIS) (THOMPSON et al., 2004), cuja função é medir a intensidade de apoio que as pessoas com deficiência intelectual requerem em habilidades adaptativas (ALMEIDA, 2013).

Os estudos realizados por Luchini, Zutião e Almeida (2015), Zutião (2016), Lopes (2016) e Zutião, Boueri e Almeida (2016) avaliaram a intensidade de apoio em comportamentos adaptativos de pessoas com deficiência, com o objetivo de incentivar o planejamento de ensino e elaborar intervenções para auxiliar na independência dessas pessoas. Todavia, apesar de o foco dos estudos serem o mesmo, foram empregados instrumentos distintos, uma vez que o estudo de Luchini, Almeida e Zutião (2015) fez uso da Escala de Intensidade de Apoio - SIS, enquanto o estudo de Zutião, Boueri e Almeida (2016) utilizou o instrumento Avaliação de Áreas Adaptativas - AAA. Já nos estudos de Lopes (2016) e Zutião (2016), além de ser medida a intensidade de apoio de pessoas com deficiência intelectual com o uso da Escala SIS, foram desenvolvidos programas de intervenção para auxiliar na independência dessas pessoas.

Nota-se um número reduzido de estudos atinentes ao uso da Escala de Intensidade de Apoio - SIS como ferramenta para elaborar o planejamento de ensino, uma vez que apenas um estudo (LUCHINI; ALMEIDA; ZUTIÃO, 2015) sugere que a escala seja para tal 
http://dx.doi.org/10.5902/1984686X44225

fim e apenas dois estudos (LOPES, 2016; ZUTIÃO, 2016) realizaram programas interventivos por meio da Escala SIS. Nos estudos citados, o público-alvo dominante foi a deficiência intelectual, e nenhuma das pesquisas foram desenvolvidas apenas para sujeitos com síndrome de Down, havendo, portanto, necessidade de mais pesquisas com este público-alvo. Salienta-se ainda que os estudos tiveram como foco promover a independência do aluno com deficiência e não auxiliar o professor em sua prática pedagógica.

As práticas pedagógicas, de acordo com Franco (2012), podem ser definidas como práticas que têm como objetivo concretizar o processo educacional, ou seja, essas práticas devem se organizar para atender a um objetivo educacional. $O$ aluno terá acesso ao currículo escolar por meios das práticas pedagógicas e cabe ao professor verificar e organizar os conteúdos para transmiti-los a seus alunos. Desse modo, para Franco (2015), uma aula é considerada uma prática pedagógica quando é organizada com intencionalidade, reflexão para verificar se todos estão participando, e com os meios para atingir os objetivos propostos.

Uma prática pedagógica considerada eficaz é aquela sobre a qual o professor está constantemente refletindo e planejando novas ações. Refletir e planejar é uma ferramenta que serve como base para a prática pedagógica (SANTOS; PERIN, 2013). $O$ ato de planejar é executado por todas as pessoas, podendo ser um planejamento sofisticado, como os que são realizados dentro das grandes empresas, ou simples, como o planejamento do próprio cotidiano (MENEGOLLA; SANT'ANNA, 2007).

Menegolla e Sant'anna (2007) salientam que todo planejamento inicia com uma avaliação para poder identificar uma necessidade e posteriormente traçar os objetivos a serem alcançados. Assim, para planejar é preciso percorrer cinco etapas, que são: avaliar as necessidades, definir os objetivos, determinar os recursos disponíveis, estabelecer a forma de avaliação e definir o prazo para execução.

No âmbito educacional, o planejamento não deve ser diferente. Para Santos e Perin (2013), o planejamento é uma ferramenta necessária para auxiliar o professor em sua prática pedagógica, oferecendo a ele uma maior organização do que será desenvolvido em sala de aula, possibilitando que o ensino e aprendizagem dos alunos seja eficiente. Já de acordo com Assis (2008), para que a prática do professor seja eficaz, além das qualificações deste, é preciso que ele adote alguns hábitos, sobretudo o planejamento de ensino. 
Segundo Klosouski e Reali (2008), existem quatro tipos de planejamentos na área da educação, os quais, apesar de parecerem iguais, possuem finalidades distintas: planejamento educacional, planejamento escolar, planejamento curricular e planejamento de ensino. O planejamento educacional trata-se da educação em geral, que se preocupa com a necessidade de toda a sociedade e cria estratégias para alcançar os objetivos. $\mathrm{O}$ planejamento escolar trata-se da educação dentro da instituição escolar, levando em consideração a estrutura, organização, propostas pedagógicas, enfim, todas as ações que envolvem a escola. Já o planejamento curricular trata-se das atividades que os alunos devem realizar em todas as áreas. Por fim, o planejamento de ensino é o que irá nortear o trabalho do professor, pois se refere à sua prática pedagógica dentro da sala de aula e às atividades que pretende desenvolver com seus alunos.

No estudo de Luchini, Almeida e Zutião (2015) sugere-se que sejam planejadas e implementadas intervenções pedagógicas com a Escala SIS, principalmente na área da aprendizagem ao longo da vida. Assim, a Escala de Intensidade de Apoio - SIS é indicada como instrumento norteador na elaboração de um planejamento de ensino do professor, justificando sua utilização. Portanto, seria possível obter resultados positivos ao optar-se por intervir junto ao professor, tendo como foco as necessidades de apoio nos comportamentos adaptativos em jovens com síndrome de Down para a realização das atividades?

Desse modo, tem-se como objetivos (a) avaliar a intensidade de apoio nos comportamentos adaptativos de jovens com síndrome de Down; (b) aplicar em colaboração com o professor, um planejamento de ensino a partir da necessidade de apoio.

\section{Métodos}

O estudo seguiu a abordagem qualitativa descritiva pautada na investigação ação. Foram participantes do estudo uma professora de Educação Especial, dois jovens com síndrome de Down e seus respectivos pais. A professora tinha 24 anos e possuía graduação em Licenciatura em Educação Especial e estava cursando pós-graduação em Análise do Comportamento Aplicada ao Autismo. Os jovens foram denominados pela inicial J, sendo que J1 tinha 21 anos e gênero masculino e J2 tinha 19 anos e gênero feminino. 
http://dx.doi.org/10.5902/1984686X44225

\section{Aspectos éticos}

O trabalho foi submetido e aprovado pelo Comitê de Ética em Pesquisa com Seres Humanos da Universidade Federal de São Carlos (CAEE 71735617.8.0000.5504).

Foram encaminhados aos participantes os Termos de Consentimento Livre e Esclarecido (TCLE) e Termo de Assentimento Livre e Esclarecido (TALE), sendo: um TCLE para a professora de Educação Especial; um TCLE para o aceite da participação dos pais; um TCLE para os pais autorizarem a participação dos filhos e por fim, um TALE para o aceite da participação dos jovens com síndrome de Down.

\section{Local}

A coleta de dados foi realizada em uma Associação de Pais e Amigos dos Excepcionais (APAE), de um município de médio porte, localizado no interior do estado de São Paulo.

No caso de J1, a aplicação da Escala SIS ocorreu em sua residência e com J2, a aplicação do instrumento deu-se em uma sala de aula da instituição especializada. Já os encontros para elaborar o planejamento de ensino com a professora aconteceram em uma sala de aula da instituição especializada.

\section{Instrumentos}

Para a coleta dos dados foram utilizados como instrumentos: (a) Escala de Intensidade de Apoio - SIS (THOMPSON et al., 2004), e (b) roteiro para elaboração do planejamento de ensino. A Escala SIS foi elaborada pela Associação Americana de Deficiência Intelectual e Desenvolvimento (AAIDD) em um período de cinco anos, sendo AAIDD o editor, detentor dos direitos autorais e único proprietário do instrumento. Foi utilizada para a coleta dos dados a versão traduzida para o português, porém ainda se encontra em fase de validação.

A escala é composta por três sessões, sendo: seção um com 49 atividades agrupadas em seis áreas: Vida Diária, Vida em Comunidade, Aprendizagem ao Longo da Vida, Emprego, Saúde e Segurança, Social; seção dois trata-se de atividades relacionadas à proteção e defesa e a seção três com atividades sobre necessidades de apoio médico e comportamental.

O roteiro para a elaboração do planejamento de ensino trata-se de um instrumento elaborado pela professora e pesquisadora, de acordo com os resultados obtidos por meio 
da Escala de Intensidade de Apoio, que evidenciou a área em que os jovens necessitavam de maior apoio. O roteiro para o planejamento de ensino era composto por: data da atividade, nome da atividade, objetivo, descrição das atividades a serem trabalhadas, estratégias utilizadas e avaliação.

Durante as reuniões entre a professora e a pesquisadora, foi elaborado o planejamento de ensino para os dois jovens com síndrome de Down, baseando-se na área adaptativa Aprendizagem ao Longo da Vida.

\section{Procedimento de coleta de dados}

Antes de iniciar a coleta de dados, a pesquisadora entrou em contato com a diretora da instituição de Educação Especial para apresentar o projeto de pesquisa. Com o interesse em participar do estudo, a diretora assinou a carta de anuência, para que assim, o projeto fosse enviado ao Comitê de Ética.

O trabalho foi submetido e aprovado pelo Comitê de Ética em Pesquisa com Seres Humanos da Universidade Federal de São Carlos, e em seguida, realizou-se o recrutamento dos participantes na instituição, junto à diretora e psicóloga, sendo encaminhados os termos de consentimento e assentimento

Após o aceite e assinatura dos termos, agendou-se com os pais dos jovens uma data e horário para a aplicação da Escala de Intensidade de Apoio. A aplicação da Escala de Intensidade de Apoio ocorreu na residência de J1, e com J2, nas dependências da instituição especializada. Devido ao comprometimento na fala de ambos jovens, os pais foram os respondentes da escala SIS. A pesquisadora explicou o funcionamento da escala e deixou uma chave de pontuação com cada pai/responsável. Caso o participante não compreendesse alguma pergunta, era fornecido um exemplo para facilitar.

As reuniões com a professora deram-se nas dependências da instituição especializada, sendo divididas em cinco, com duração de 50 minutos cada uma: (1) Apresentação da pesquisa e elaboração do cronograma de reuniões; (2) Apresentação da Escala de Intensidade de Apoio; (3) Apresentação dos resultados obtidos por meio da Escala de Intensidade de Apoio e verificação do conteúdo previsto para o mês seguinte; (4) Elaboração do planejamento de ensino; e, (5) Elaboração dos materiais para a intervenção.

Para a elaboração do planejamento, seguiu-se o roteiro para o planejamento de ensino, elaborado pela professora e pesquisadora. As atividades desenvolvidas visavam compor o conteúdo que seria trabalhado pela professora, que no caso era a temática 
http://dx.doi.org/10.5902/1984686X44225

Trânsito. A intervenção durou 15 dias, sendo sete dias de reuniões com a professora para elaborar do planejamento de ensino e oito dias para a aplicação das atividades.

As atividades ocorreram no período da tarde, na sala de aula, após a professora realizar as atividades rotineiras: chegada dos alunos, acomodação em classe; chamada; cabeçalho; calendário; lavar as mãos; intervalo; retorno para a classe; escovação; atividade; guardar material; organização da sala de aula; ir para o ônibus. A intervenção deu-se com todos os alunos da sala de aula, porém com foco nos dois jovens com síndrome de Down.

\section{Procedimento de análise dos dados}

Os resultados foram organizados e analisados de forma qualitativa. Para análise da Escala SIS, foi utilizado o manual da mesma (THOMPSON et al., 2004), considerando-se o tipo, frequência e tempo diário de apoio. O planejamento de ensino foi elaborado a partir do resultado da Escala SIS, que apresentou a área Aprendizagem ao Longo da vida como sendo a que os jovens necessitavam de maior apoio. Foram organizadas duas categorias de análise fundamentadas nos temas abordados: (a) necessidade de apoio nos comportamentos adaptativos dos jovens com síndrome de Down e (b) planejamento de ensino a partir da necessidade de apoio.

\section{Resultados e discussões}

\section{Necessidade de apoio nos comportamentos adaptativos dos jovens com síndrome de Down}

Esta categoria objetivou descrever os resultados obtidos por meio da Escala de Intensidade de Apoio pelos dois jovens participantes com síndrome de Down. Os gráficos na figura 1 apresentam em cada coluna a pontuação nas áreas: Vida Diária, Vida em Comunidade, Aprendizagem ao Longo da Vida, Emprego, Saúde e Segurança, Social. A pontuação geral dos níveis de apoio pode ser de 1 a 20, sendo que, de 1 a 5 , o nível de apoio é considerado baixo; de 6 a 8 intermediário; de 9 a 12 alto e de 13 a 20, muito alto, ou seja, quanto maior a pontuação, maior a necessidade de apoio. 
http://dx.doi.org/10.5902/1984686X44225

Figura 1 - Resultados da Escala de Intensidade de Apoio (SIS) dos dois jovens participantes. Os participantes foram identificados por meio da letra $\mathrm{J}$ e de seu respectivo número

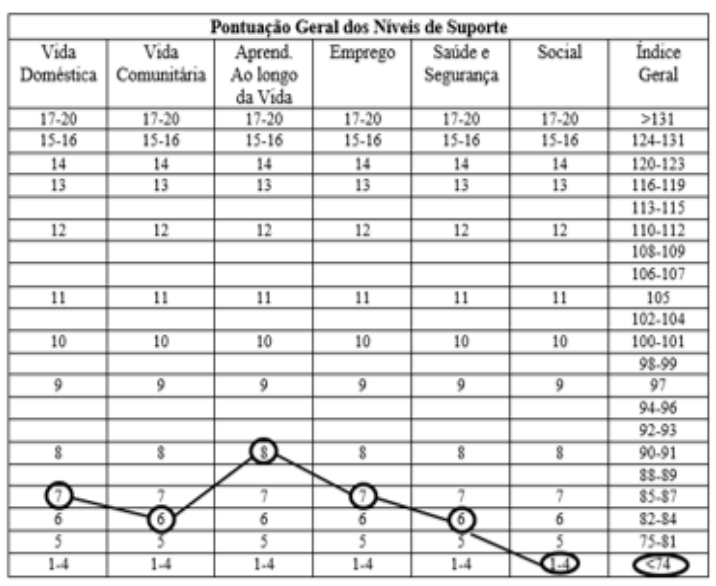

Identificação J1

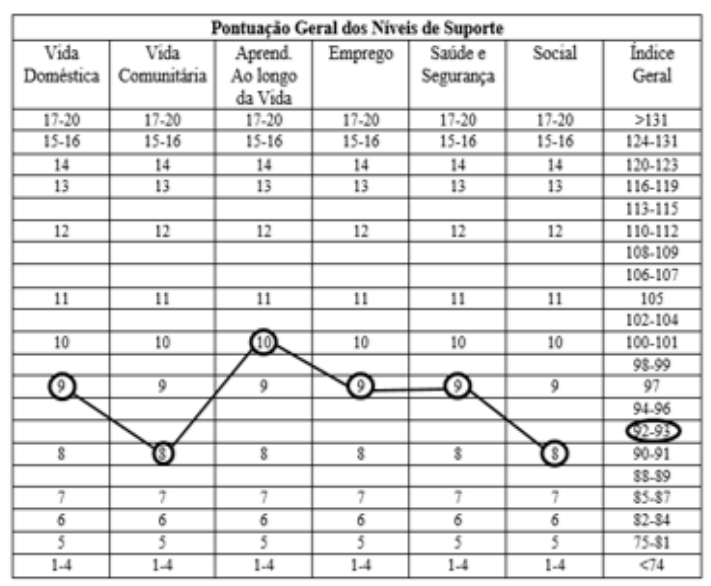

Identificação J2

Fonte: molde gráfico retirado do manual da Escala de Intensidade de Apoio (THOMPSON, 2004) preenchido pela autora com os resultados obtidos (2018).

Observando o gráfico, constata-se que $\mathrm{J} 1$ necessita de apoio intermediário nas áreas de vida doméstica, vida comunitária, aprendizagem ao longo da vida, emprego e saúde e segurança e de apoio baixo na área social.

Em vida doméstica, o jovem não necessita de apoio nas atividades de utilizar o banheiro, alimentar-se, vestir-se, tomar banho/cuidar da higiene, além de conseguir utilizar aparelhos eletrodomésticos e eletrônicos, mas necessita de ajuda física total para cuidar da roupa, preparar alimento e cuidar/limpar a casa.

$\mathrm{Na}$ área de vida comunitária, $\mathrm{J} 1$ tem autonomia para interagir com as pessoas da comunidade, sendo esta atividade a única que ele realiza sem apoio.

Em aprendizagem ao longo da vida, J1 não necessita de apoio para interagir com outras pessoas em atividades de aprendizagem e necessita de monitoramento para acessar contextos educacionais e de formação. Para aprender estratégias de autogerenciamento, é necessário oferecer pistas verbais/gestuais e the é oferecido apoio físico total em diversas atividades, como: participar nas decisões sobre a própria educação e formação, aprender e usar estratégias para resolução de problemas, utilizar tecnologia para aprender, assimilar competências acadêmicas funcionais, aprender habilidades para a saúde e habilidades de autodeterminação.

$\mathrm{Na}$ quarta área avaliada, que envolvem atividades ligadas ao emprego, como o participante nunca exerceu atividade remunerada, foi preciso que o pai respondesse as questões baseando-se no que conhecia sobre o filho e supondo como ele se comportaria 
http://dx.doi.org/10.5902/1984686X44225

diante de tais situações. Assim, J1 não necessita de apoio em três atividades, sendo: interagir com os colegas, interagir com supervisores e procurar assistência e informação do empregado.

Em saúde e segurança, J1 tem autonomia para deslocar-se, aprender e ter acesso aos serviços de emergência e para manter o bem-estar emocional. Já para tomar medicamentos, manter uma dieta nutritiva e equilibrada e manter a saúde e boa forma física, é preciso que alguém esteja sempre o monitorando.

Por fim, na última área analisada, que envolvem atividades sociais, o jovem apresentou autonomia em quase todas as atividades, como socializar-se no ambiente doméstico e fora dele, estabelecer e manter amizades, envolver-se em relacionamento amoroso, participar de atividades de recreação e lazer com outras pessoas, entre outras.

Tratando-se dos resultados da participante $\mathrm{J} 2$, verifica-se que a mesma necessita de apoio intermediário nas áreas vida comunitária e social e de apoio alto nas áreas vida doméstica, aprendizagem ao longo da vida, emprego, saúde e segurança.

$\mathrm{Na}$ área vida comunitária, J2 não realiza com autonomia nenhuma das atividades, e a necessidade de apoio oferecida variou desde monitoramento até apoio físico total.

$\mathrm{Na}$ área de aprendizagem ao longo da vida, a necessidade de apoio constatada com maior frequência foi físico total, envolvendo atividades como: participar nas decisões sobre sua educação e formação, aprender e usar estratégias para resolução de problemas, utilizar tecnologia para aprender, aprender habilidades para saúde e habilidades de autodeterminação. A menor necessidade de apoio oferecida foi o monitoramento, na atividade de acessar contextos educacionais e de formação. Já para interagir com outras pessoas em situação de aprendizagem, aprender competências acadêmicas funcionais e aprender estratégias de autogerenciamento, a necessidade de apoio foi físico parcial.

Em atividades vinculadas ao emprego, assim como foi realizado com $\mathrm{J} 1$, devido à participante nunca ter exercido atividade remunerada, a mãe respondeu às questões baseando-se no que conhecia sobre a filha e no que supunha como ela se comportaria diante de tais situações. Dessa forma, J2 não necessita de apoio para interagir com os colegas de trabalho.

Em relação saúde e segurança, a jovem não necessita de apoio para deslocar-se, porém necessita do apoio monitoramento para tomar medicação, manter uma dieta nutritiva e equilibrada e manter o bem-estar emocional. 
Por fim, na última área avaliada, relacionadas às atividades sociais, a jovem realiza com autonomia duas atividades, sendo estas socializar-se no ambiente doméstico e comunicar, aos outros, suas necessidades pessoais.

Com a análise de cada jovem, é possível identificar que a área em que $\mathrm{J} 1$ necessita de menor apoio foi em social, com pontuação 1-4 e, no caso de J2, foi a da vida comunitária e social, obtendo-se pontuação 8 , a qual já é considerada intermediária. Analisando a área em que houve maior necessidade de apoio, tem-se para ambos os jovens a área Aprendizagem ao Longo da Vida, na qual J1 obteve pontuação 8 e J2 pontuação 10

Neste sentido, Thompson et al. (2004) apontam que os resultados da Escala de Intensidade de Apoio - SIS auxiliam a identificar a necessidade de apoio para constituir um planejamento centrado no indivíduo. Esse planejamento deve ser composto por quatro itens: identificação dos interesses; avaliação da intensidade das necessidades de apoio; elaboração do planejamento de ensino individualizado e monitoramento do progresso do planejamento. Além disso, realizar entrevistas com o indivíduo, com sua família e com as pessoas que o apoiam auxilia na identificação das necessidades e desejos (THOMPSON et al., 2004).

Constata-se nos resultados que o nível de apoio do participante $\mathrm{J} 1$ variou entre baixo e intermediário, obtendo-se no máximo pontuação 8, e o da participante J2 variou entre intermediário e alto, obtendo-se no máximo pontuação 10.

\section{Planejamento de ensino a partir da necessidade de apoio}

O planejamento de ensino ocorreu a partir do diálogo entre professora e pesquisadora com base nos resultados da Escala de Intensidade de Apoio. A professora apresentou o planejamento anual dos conteúdos a serem desenvolvidos ainda com a classe e com base nesses conteúdos previstos, foi selecionado o tema "Trânsito" para fazer parte do planejamento de ensino dos jovens com síndrome de Down, pois esta temática, segundo os relatos da professora, tem o objetivo de trabalhar e conscientizar os alunos sobre as normas de trânsito, alertando sobre os possíveis perigos e importância de respeitar às normas.

Segundo os relatos da professora, os alunos com síndrome de Down atravessam a rua sem atenção e apresentam dificuldade para observarem a existência de placas de sinalização. Diante disso, pesquisadora e professora verificaram se o conteúdo se adequava na área de maior apoio. 
Dessa forma, foram elaboradas atividades com objetivos específicos, a partir do conteúdo que constava no plano de ensino da professora, para serem aplicadas durante oito dias, de forma a trabalhar as seguintes atividades da área adaptativa Aprendizagem ao Longo da Vida: interagir com outras pessoas em atividades de aprendizagem; utilizar tecnologia para aprender; aprender competências acadêmicas funcionais (mediante slides, aplicativos no computador, jogos e atividade extraclasse).A primeira atividade teve como objetivo apurar o conhecimento dos alunos sobre o trânsito (leis básicas, função do semáforo, placas de trânsito). A professora apresentou o tema e dividiu a turma em dois grupos para apresentar um vídeo sobre direção defensiva. O participante $\mathrm{J} 1$ dispersava-se quando ouvia algum barulho do lado de fora da sala de aula, porém logo voltava sua atenção para o vídeo. Já a participante J2 não tirou os olhos do notebook.

De acordo com Sá, Campos e Lima (2007), o uso do computador é benéfico para as pessoas com deficiência, pois estimula as funções cognitivas, incrementa a formação e armazenamento de ideias, conhecimentos, informações e na concepção da realidade.

Assim como o computador, os vídeos também podem ser tomados como ferramenta educacional que ajudará no processo de aprendizagem, pois irá trabalhar o conteúdo de uma forma mais criativa e diversificada, atraindo a atenção dos alunos (PAZZINI; ARAÚJO, 2013). Os autores ainda indicam que é preciso que os vídeos sejam adicionados como recurso complementar ao que será ensinado e não como uma forma de entretenimento sem objetivo.

Após assistirem ao vídeo, a professora fez uma roda de conversa com os alunos e, utilizando slides e a lousa, deu uma aula expositiva para os alunos. A professora mostrou algumas placas de trânsito e, enquanto explicava, interagia com os alunos fazendo perguntas, tais como: se já haviam visto um semáforo para pedestres e qual era sua funcionalidade, se sabiam quais eram as cores do semáforo e a função de cada cor, e alertou também sobre a importância de andarem sempre na calçada.

Embora os participantes tenham interagido pouco durante a aula, ambos ficaram atentos à explicação da professora. No caso de $\mathrm{J} 1$, apesar de não responder corretamente ao significado da placa, ele soube identificar o que estava desenhado e também relacionar o desenho com algo presente em seu dia a dia. Assim como J1, apesar de J2 não ter respondido às questões, ela interagiu de forma alegre com a professora e também não se dispersou durante a aula, o que pode ser considerado um avanço, uma vez que na observação inicial a jovem ficava com a cabeça apoiada em sua mesa. 
http://dx.doi.org/10.5902/1984686X44225

$\mathrm{Na}$ segunda atividade, a professora iniciou a aula fazendo uma revisão sobre o que haviam aprendido no dia anterior e apresentou em slides novas placas, explicando a diferença entre elas (placas de regulamentação, advertência, etc.). Para Silva (2017), é importante revisar o conteúdo com os alunos com deficiência intelectual, pois irá facilitar na aprendizagem. Para Cunha e Santos (2007) a repetição de conteúdo, além de agir como facilitador na aprendizagem, ajuda a "enganar" o cansaço e a falta de atenção.

A atividade, que consistia em colorir desenhos ligados ao trânsito (placas, semáforos, faixa de pedestres, etc.), recortar e colar em um cartaz para fixar no mural da escola. Para que os dois jovens exercessem as atividades, foi necessário que a professora contornasse o desenho com a cor correspondente. Alguns alunos, para compreender um conteúdo ou realizar uma atividade, necessitam que seja explicado passo a passo, sendo papel do professor diminuir tais dificuldades (DOMINGUES; OLIVEIRA, 2016). Para tanto, é preciso que o professor conheça seus alunos, suas capacidades, comportamentos e preferências para oferecer atividades que consigam realizar e sejam significativas (ALMEIDA, 2018).

A professora perguntou se $\mathrm{J} 1$ tinha conhecimento sobre o nome das cores (vermelho e preto) e se sabia qual o significado da placa. Como não soube responder, a professora explicou novamente e perguntou onde deveria pintar de vermelho e de preto, conforme 0 contorno, e ele apontou corretamente cada local, repetindo as cores ditas. No desenho da faixa de pedestres, também Ihe foi perguntado qual cor era aquela, J1 disse que era a cor vermelha; porém a professora o corrigiu. Ao perguntar o significado da placa, o jovem respondeu "andando" e fez um movimento com a mão indicando que era uma pessoa andando. Quando J1 terminou o desenho da faixa de pedestres, mostrou para a pesquisadora e disse que a cor era azul.

No caso de J2, a professora entregou o desenho de um semáforo, também contornado com suas respectivas cores e separou os três lápis de cor que ela iria utilizar para a pintura (vermelho, amarelo e verde). Todavia, J2 queria escolher os lápis de cor para pintar, sendo necessário a professora retomar a explicação sobre a função de cada cor do semáforo. Assim, ela coloriu a imagem e interagiu com sua colega de mesa, sorrindo e fazendo carinho em seu braço.

Os dois jovens participaram de todas as atividades, mesmo com comunicação limitada tentaram responder às perguntas da professora, coloriram seus desenhos e interagiram com seus colegas. A professora, além de explicar a atividade de forma geral para a turma, também explicou individualmente para os jovens. De acordo com Troncoso e Cerro (2004), 
http://dx.doi.org/10.5902/1984686X44225

as pessoas com síndrome de Down aprendem com mais facilidade quando recebem atenção individual. Para Vygotsky (1987), as pessoas com deficiência são capazes de desenvolverem-se, mas para tanto devem ser fornecidas condições adequadas para elas.

A atividade do terceiro dia consistia em fazer um passeio com os alunos para conhecerem o trânsito nas proximidades da escola e visualizar as placas reais de sinalização. Quando o processo de ensino-aprendizagem ocorre em ambientes não formais possibilita que o aluno contextualize o conhecimento aprendido em sala de aula, podendo ser mais eficiente na compreensão do conteúdo, além de ser estimulado a interagir (MOREIRA; MASINI, 2001; XAVIER; ARRUDA, 2008).

Cunha e Santos (2007) salientam que os jovens com síndrome de Down compreendem o mundo de forma mais significativa por meio do sentido visual, sendo importante que lhes sejam dadas oportunidades de experiências visuais enriquecedoras e que façam parte do seu dia a dia.

A primeira placa encontrada foi a de proibido estacionar. Uma aluna fez a identificação da placa, e J1 disse a cor vermelha, aludindo à cor do círculo na placa. Um pouco mais para frente, havia uma lombada e a respectiva placa de advertência, nenhum aluno soube identificar, porém J1 identificou a cor, dizendo amarelo. Outra placa que havia na rua era a de permitido estacionar - vaga para deficientes físicos. Quando J1 viu a placa, disse "carrinho" referente à cadeira de rodas.

Na placa de PARE, J1 não soube identificar o significado, porém disse a cor vermelha. A professora pediu para que $\mathrm{J} 2$ repetisse a palavra "pare" e ela pronunciou "pa" e fez um sinal para parar com a mão.

Quando a professora mostrou a placa alusiva à rotatória, ela perguntou se alguém sabia dizer o significado do desenho da placa, e J1 respondeu "balão" e disse "ali" apontando com a mão no sentido de que estava mais para frente (onde havia uma rotatória); e a professora o parabenizou, pois, apesar de não usar o nome correto, o jovem soube relacionar a placa com a rotatória que havia nas proximidades.

Durante o processo de aprendizagem, o professor não deve exigir que os alunos emitam respostas padronizadas, mas sim deve ensiná-los de formas diferentes e compreender que cada aluno irá responder de um jeito (ANACHE, 2012). Cada jovem com síndrome de Down tentou responder às perguntas da professora e, mesmo que tenham utilizado termos diferentes do esperado, a professora os parabenizou. Neste caso, a atitude da professora em parabenizá-los é de suma importância no ensino, visto que um 
http://dx.doi.org/10.5902/1984686X44225

comportamento quando elogiado poderá auxiliar no sucesso dos alunos, pois irão sentir-se motivados (CABELEIRA, 2013).

A atividade planejada para o quarto dia consistia em montar um quebra-cabeça relacionado ao trânsito, com imagens reais do município dos jovens. A atividade teve como objetivo conhecer e aprender a solucionar problemas por meio do quebra-cabeça, trabalhar a socialização e coordenação motora fina.

A professora formou duplas e os participantes $\mathrm{J} 1 \mathrm{e} \mathrm{J} 2$ ficaram em duplas distintas. Primeiramente, ela mostrou a imagem do quebra-cabeça no computador e explicou que, depois de montarem, a imagem ficaria igual àquela. Ela ajudou todas as duplas, começando por J1 e T. (colega de sala e par de J1), deixando com que um aluno por vez pegasse uma peça para encaixar. Quando J1 escolhia uma peça errada, ela colocava no quebra-cabeça para ele visualizar que não era a peça correta, que a peça escolhida por ele não formava a imagem igual ao exemplo e pedia para ele pegar outra. Em cada peça correta encaixada por J1 ele demonstrava grande felicidade, querendo mostrar o que havia feito para todos.

Após montarem, a professora pediu para que colassem pecinha por pecinha em uma folha de sulfite. J1 colocava pingos de cola em cada ponta da peça e colava na folha sulfite, às vezes deixando um espaço entre uma peça e outra, porém conseguiu realizar a proposta.

No caso da dupla de J2, a professora percebeu que a colega T. estava ajudando J2, deixando-a escolher uma pecinha e mostrando se estava correta ou não. Assim, a professora decidiu não interferir e deixar as alunas interagindo, mas sempre de olho caso precisassem de ajuda. Quando terminaram, as duas alunas bateram palmas e fizeram um cumprimento tocando as mãos uma da outra, felizes. Na hora de colarem as peças, T. deixou a participante $\mathrm{J} 2$ colocar a cola, porém em alguns momentos ela colocava uma grande quantidade e, quando isso acontecia, as duas riam e T. a ajudava a espalhar a cola. Em concordância com a atitude colaborativa entre as alunas, Cunha e Santos (2007) considera que o trabalho em grupo é uma estratégia positiva, que promove a interação entre os alunos, gerando um clima de amizade e colaboração.

Por meio dos jogos, os alunos com deficiência aprendem a compreender regras, além de criar hábitos de convivência por estarem trabalhando em grupo, sendo tais características essenciais para viver na sociedade (MIRANDA; PINHEIRO, 2013). Desse modo, utilizar o jogo como recurso pedagógico é benéfico para os alunos com deficiência 
intelectual, pois permite que eles aprendam de acordo com suas capacidades e fiquem mais motivados em participar das atividades (KASHIMOTO, 2005).

No quinto dia, a atividade consistia em utilizar o aplicativo Google Maps, com o intuito de verificar se os jovens reconheciam a casa e o bairro onde moravam, assim como o trânsito ao redor, e trabalhar a coordenação motora fina por intermédio do computador.

Para Carneiro e Costa (2017) a tecnologia pode ser empregada como recurso pedagógico, pois contribui no processo de escolarização das pessoas com deficiência intelectual, visto que, além de auxiliar no desenvolvimento de diversas áreas do conhecimento, coloca o sujeito como protagonista.

De início, a professora explicou brevemente o que era o aplicativo Google Maps e se alguém o conhecia, porém, nenhum aluno respondeu. Em seguida, ela pegou o endereço de cada jovem em suas agendas para colocar no aplicativo, e os jovens deveriam identificar seu bairro/casa.

Ao colocar o endereço do participante $\mathrm{J} 1$, ele rapidamente reconheceu a rua de sua casa. A professora o chamou para manusear o computador, ajudando-o a movimentar o mouse. O jovem dizia para a professora "pra lá, pra lá" para ela localizar sua casa. Quando encontrou, ele gritou "mamãe" e também "carro papai" referindo-se ao carro do pai que estava na garagem. $\mathrm{J} 1$ ficou feliz ao ver sua casa no notebook, pois levantou de sua carteira e foi cumprimentar todos os colegas.

A professora ajudou $\mathrm{J} 1$ a utilizar o mouse para percorrer sobre a rua de sua casa à procura de placas de sinalização. O participante identificou ainda em sua rua uma rotatória e disse "balão", e a professora o parabenizou. Também foram localizadas algumas placas que não haviam sido apresentadas, e a professora explicou cada uma.

Enquanto a professora mostrava a casa dos outros alunos, J2 várias vezes levantou a mão pedindo para a professora mostrar sua casa. Quando a casa apareceu, a jovem riu e disse a palavra "mamãe" e também levantou sorrindo para cumprimentar os colegas, demonstrando felicidade.

A atividade prevista para o sexto dia era um jogo de dominó do trânsito, que teve como objetivo desenvolver o raciocínio dos alunos ao relacionar as imagens iguais, além de relembrar as placas de sinalização e estimular a interação entre eles.

A professora explicou o funcionamento e regras do jogo e distribuiu as peças. Nas vezes de $\mathrm{J} 1$ jogar, ele olhava atentamente para suas peças e para a que estava no centro da mesa, verificando se tinha a peça que estava sendo pedida ou se era preciso "comprar" 
no monte. Quando ele tinha, relacionava rapidamente e colocava a pecinha ao centro; porém, quando percebia que não tinha, J1 escolhia uma peça aleatória. Quando isso ocorria, a professora intervia, pedindo para ele olhar se a peça escolhida era igual à que estava na mesa, fazendo com que $\mathrm{J} 1$ identificasse que eram diferentes.

$\mathrm{O}$ caso de J2 não foi muito diferente. Nas suas vezes de jogar, ela também olhava atentamente para as peças e quando percebia que tinha alguma delas, ela entregava a peça para a professora colocar na mesa. Por mais que incentivasse a jovem a colocar a peça no devido lugar, ela preferiu entregar à professora. Quando percebia que não tinha, ela olhava e dizia "na", que significava "não", mas recusava-se a comprar mais peças.

Os alunos gostaram tanto do jogo que pediram para jogar mais vezes. Em duas rodadas, J2 venceu, o que a deixou muito feliz. Por meio do jogo, o aluno com deficiência intelectual poderá desenvolver a autonomia, linguagem, organizará seu pensamento para vencer em cada jogada, além de estimular a interação entre os colegas e aprender sobre regras (MIRANDA; PINHEIRO, 2013).

No sétimo dia, foram planejadas duas atividades em folha sulfite sobre pareamento. Na primeira atividade, os jovens tinham que pintar o semáforo com suas respectivas cores e relacionar as cores com a ação do motorista. Já na segunda atividade, os jovens tinham que relacionar as placas de sinalização com sua forma geométrica. Para os jovens realizarem ambas as atividades, a professora contornou os desenhos com suas respectivas cores e pontilhou o nome para os alunos cobrirem.

$\mathrm{Na}$ primeira atividade (semáforo), J1 cobriu o pontilhado de seu nome sem dificuldades. A professora perguntou se $\mathrm{J} 1$ se recordava sobre a função de um semáforo, mas como o jovem não conseguiu se lembrar, ela explicou novamente. Apesar de J1 não se lembrar, ele reconheceu a cor vermelha e pegou os lápis referentes a cada cor do semáforo, de acordo com o contorno do desenho.

Para o aluno compreender e realizar a atividade, a professora fazia perguntas como: Qual motorista está parado com o carro? Qual motorista está andando com o carro? Fazendo tais perguntas, o participante apontava e a professora the pedia para fazer um traço ligando as duas figuras.

J2 de início resistiu em realizar a atividade; no entanto, após muita insistência da professora, ela cobriu o pontilhado de seu nome. J2 não soube responder a respeito do funcionamento do semáforo e também não reconheceu as cores sozinha. Assim, a 
http://dx.doi.org/10.5902/1984686X44225

professora pegava um lápis de cor aleatório e perguntava se a cor do contorno era igual ao lápis. Dependendo da cor mostrada, a jovem assentia ou negava com a cabeça.

Ao ser questionada sobre a ação do motorista com a cor do semáforo, J2 respondeu apontando somente para o motorista que estava parado. A professora pegou em sua mão para fazer a ligação entre as figuras; entretanto, J2 quis fazer sozinha, e a professora fez uma linha tracejada para a aluna cobrir.

$\mathrm{Na}$ segunda atividade proposta, a professora explicou para J1 o que deveria ser feito, permanecendo ao seu lado para ajudá-lo. Para facilitar, ela apresentava uma placa e uma forma geométrica e perguntava se elas eram iguais, levando em consideração o formato. J1 olhava atentamente para as figuras e respondia sim ou não, contudo ele soube relacionar todas as figuras. De forma a auxiliar J1, a professora fez um risco tracejado para que ele cobrisse e, após ter finalizado, ele coloriu as figuras de acordo com o exemplo que a professora havia deixado.

Logo que a professora entregou a folha de atividade, J2 imediatamente reconheceu a placa de "PARE" e gritou "pa". A professora explicou a atividade para a jovem da mesma forma que havia explicado para J1, todavia ela não se concentrava e ficava rindo e segurando a mão da sua colega. Dessa forma, para ajudar J2, a professora fez a linha tracejada ligando as figuras para a jovem cobrir e ficou a seu lado para que ela terminasse a atividade.

Em ambos os casos, a ajuda oferecida pela professora foi fundamental para a realização da atividade.

No oitavo e último dia da intervenção, foi elaborado um jogo da memória com imagens ligadas ao trânsito. A professora montou um grupo com seis alunos e explicou as regras do jogo. Segundo Cunha e Santos (2007), as atividades quando realizadas em grupo permite que os alunos aprendam comportamentos adequados à sua faixa etária e ajuda no desenvolvimento da linguagem e interação social.

Conforme os jovens retiravam uma peça, a professora pedia para que a mostrassem a todos e lhes perguntava se sabiam qual placa era aquela. Quando ninguém respondia ou errava a resposta, ela dizia o nome e a funcionalidade da placa e, após sua explicação, o jogo continuava. Para achar o par, a professora pedia para os alunos retirarem outra peça e verificassem se elas eram iguais.

No início do jogo, os participantes ainda não haviam compreendido as regras, pois não esperavam a vez de cada um e viravam várias peças juntas. Após jogarem algumas 
http://dx.doi.org/10.5902/1984686X44225

rodadas com o auxílio da professora, eles foram compreendendo que tinham que esperar para jogar e que deveriam virar duas peças iguais para formar um par. Conforme apontado por Miranda e Pinheiro (2013), o jogo incita o aluno a organizar seu pensamento para compreender as regras e também a respeitar os colegas.

J1 olhava atento para cada peça que retirava, comparando-as e, quando formava par sem a ajuda da professora, ele gritava de alegria e cumprimentava os colegas. Assim como J1, J2 pegava suas peças sozinha e olhava atenta para ver se eram iguais ou diferentes, cumprimentando a professora e rindo quando encontrava duas iguais.

\section{Conclusões finais}

Este estudo objetivou avaliar a intensidade de apoio nos comportamentos adaptativos de jovens com síndrome de Down e em colaboração com a professora, elaborou e aplicou um planejamento de ensino a partir da necessidade de apoio.

No que concerne à intensidade de apoio que os jovens requerem para efetuar as atividades adaptativas, entrevê-se que o nível de apoio do participante J1 variou entre baixo e intermediário e da participante J2 variou entre intermediário e alto, salientando que ambos os jovens necessitam de maior apoio na área de Aprendizagem ao Longo da Vida. Tais dados são indicativos de que os jovens não estão realizando atividades adaptativas com autonomia, muitas vezes pela falta de oportunidade e superproteção da família.

Quanto a elaboração e aplicação do planejamento de ensino a partir da necessidade de apoio, foram verificadas diferenças no comportamento dos participantes, pois, em ambos os casos, viu-se uma maior concentração e envolvimento nas atividades, por meio de respostas verbais/gestuais, e também a resolução das atividades propostas. Com o uso dos jogos e atividades em grupo a interação entre os alunos aumentou, bem como o relacionamento com a professora.

Supõe-se que a mudança constatada em ambos os participantes pode ter ocorrido devido ao fato de terem sido utilizados recursos diferenciados, como computador, slides, vídeos, jogos e atividades extraclasse, o que pode ter deixado a aula mais motivadora, pois o uso de tais recursos não fazia parte da rotina das aulas. Os dados desse estudo evidenciam que ter elaborado e seguido um planejamento pode ter cooperado para a mudança de atitude dos jovens com síndrome de Down, pois os mesmos tinham conhecimento do que seria trabalhado a cada dia, tornando assim o ensino mais atrativo e organizado. 
Ao olhar para a prática pedagógica, conclui-se que é preciso que o professor torne o ensino mais atrativo, para os alunos com deficiência intelectual, por meio de recursos funcionais.

Conclui-se, ainda que, avaliar a intensidade de apoio nos comportamentos adaptativos de jovens com síndrome de Down por meio da Escala de Intensidade de Apoio auxilia no planejamento, visto que o instrumento apresenta os níveis das necessidades de apoio em cada uma das áreas adaptativas, direcionando o planejamento das atividades, atendando-se nas necessidades e capacidades de cada aluno. Assim, compreende-se que o planejamento de ensino é uma ferramenta importante e indispensável, tanto na prática pedagógica dos professores como no processo de aprendizagem dos alunos.

Espera-se que os dados aqui apresentados auxiliem e motivem os pesquisadores a desenvolver novos estudos por intermédio da Escala de Intensidade de Apoio como ferramenta norteadora de um planejamento de ensino capaz de contribuir para o trabalho docente.

\section{Referências}

ALMEIDA, Flávio Aparecido de. A inclusão de alunos com deficiência intelectual na rede regular de ensino. Psicologia Pt., Minas Gerais, p. 1-7, 2018.

ALMEIDA, Maria Amelia. O caminhar da Deficiência Intelectual e Classificação pelo Sistema de Suporte/Apoio. In: SÃO PAULO. Secretaria da Educação. Núcleo de Apoio Pedagógico Especializado - CAPE. ALMEIDA, M.A. (Org.). Deficiência Intelectual: Realidade e ação. São Paulo: SE, 2012. p. 51-63.

ALMEIDA, Maria Amelia. Projeto: Adaptação e validação da escala de intensidade de suporte - SIS para o Brasil: uma contribuição para avaliação funcional de jovens e adultos com deficiência intelectual. Financiamento CNPq - Processo: 409129/2013-5. Chamada: 43/2013 - Ciências Humanas, Sociais e Sociais Aplicadas.

AMERICAN, Psychiatric Association. Deficiências Intelectuais. In: Manual diagnostico e estatístico de transtornos mentais: DSM-5. Artmed: Porto Alegre, 2014, p. 74-82.

ANACHE, Alexandra Ayach. Avaliação da aprendizagem de alunos com deficiência intelectual na perspectiva da educação inclusiva. In: MENDES, E.G.; ALMEIDA, M.A. (Org.). Dimensões Pedagógicas nas Práticas de Inclusão Escolar. Marília: ABPEE, 2012, v.2, p. 179-195.

ASSIS, Renata Machado de. Planejamento de ensino: algumas sistematizações. Revista Eletrônica de Educação do Curso de Pedagogia do Campus Jataí da Universidade Federal de Goiás. v. 1, n. 4, jan/jul, 2008. 
BRASIL, Ministério da Saúde. Secretaria de Atenção à Saúde. Departamento de Ações Programáticas Estratégicas. Diretrizes de atenção à pessoa com Síndrome de Down. 1 ed., 1. reimp. - Brasília: Ministério da Saúde, 2013. 60 p.

CABELEIRA, João Pedro Rodrigues. Reforço positivo e aprendizagem cooperativa: estratégias facilitadoras do sucesso de alunos desmotivados. 2013. 75 f. Dissertação (Mestrado Ensino das Artes Visuais) - Universidade Lusófona de Humanidades e Tecnologias, Lisboa, 2013.

CARNEIRO, Relma Ureu Carbone; COSTA, Maria Caroilina Branco. Tecnologia e deficiência intelectual: práticas pedagógicas para inclusão digital. Revista online de Política e Gestão Educacional, Araraquara, v.21, n. esp. 1, p. 706-719, out, 2017.

CUNHA, Maria Isabel Santo de Miranda; SANTOS, Luisá Maria Nogueira. Aprendizagem Cooperativa na Deficiência Mental (Trissomia 21). Cadernos de Estudo. N. 5, p. 27- 43, 2007.

DOMINGUES, Rosely; OLIVEIRA, Flávio Medina de. Adaptação de conteúdos e avaliação para alunos com DI. Cadernos PDE. Paraná, v. 1, 2016.

FERREIRA, Elizângela Fernandes; MUNSTER, Mey de Abreu Van. Métodos de avaliação do comportamento adaptativo em pessoas com deficiência intelectual: uma revisão de literatura. Revista Educação Especial, v. 28, n. 51, p. 193-208, jan./abr. 2015.

FRANCO, Maria Amelia Santoro. Práticas Pedagógicas nas Múltiplas Redes Educativas. In: LIBÂNEO, José Carlos; ALVES, Nilda. (Org.). Temas de Pedagogia: diálogos entre didática e currículo. São Paulo: Cortez, 2012. P. 169-188.

FRANCO, Maria Amelia Santoro. Práticas pedagógicas de ensinar-aprender: por entre resistências e resignações. Educ. Pesqui. São Paulo, v. 41, n. 3, p. 601-614, set. 2015.

KISHIMOTO, Tizuko Morchida. Jogo, Brinquedo, Brincadeira e a Educação. 8. ed. São Paulo: Cortez, 2005.

KLOSOUSKI, Simone Scorsim; REALI, Klevi Mary. Planejamento de ensino como ferramenta básica do processo ensino-aprendizagem. Revista Eletrônica Lato Sensu, v. 9, n. 1, 2008.

KOZMA, Chahira. O que é a síndrome de Down?. In: STRAY-GUNDERSEN, K. Crianças com síndrome de Down: guia para pais e educadores. 2. ed. Porto Alegre:Artmed. p.1542, 2007.

LOPES, Betania Jacob Stange. Programa de Transição para a vida adulta de jovens com deficiência intelectual em ambiente universitário. $246 \mathrm{f}$. Tese de doutorado (Programa de Pós-Graduação em Educação Especial) - Universidade Federal de São Carlos, São Carlos, 2016. 
LUCHINI, Heliane Rampaso; ZUTIÃO, Patrícia; ALMEIDA, Maria Amelia. Avaliação de comportamentos adaptativos e qualidade de vida jovens e adultos com deficiência intelectual. Anais do VII Congresso Brasileiro de Educação Especial e X Encontro de Pesquisadores em Educação Especial, 2015.

MENEGOLLA, Maximiliano; SANT'ANNA, Ilza Martins. Por que planejar? Como planejar? 15. ed. Rio de Janeiro: Vozes, 2007, p. 11-58.

MIRANDA, Amanda Drzewinski de; PINHEIRO, Nilcéia Aparecida Maciel. O jogo como estratégia metodológica no ensino da numeração para crianças com deficiência intelectual. In: XI Encontro Nacional de Educação Matemática. Anais... Curitiba, 2013, p. 1-10.

MOREIRA, Marco Antonio; MASINI, Elcie F. Salzano. Aprendizagem significativa: a teoria de David Ausubel. São Paulo: Centauro, 2001.

PAZZINI, Darlin Nalú Avila; ARAÚJO, Fabrício Viero. O uso do vídeo como ferramenta de apoio ao ensino-aprendizagem. Santa Maria: UFSM. Curso de especialização em Mídias na Educação, 2013.

SÁ, Elizabet Dias de; CAMPOS, Izilda Maria de; SILVA, Myriam Beatriz Campolina. Atendimento Educacional Especializado: Deficiência Visual. SEESP/SEED/MEC. Brasília-DF, 2007.

SANTOS, Maria Lucia; PERIN, Conceição Solange Bution. A importância do planejamento de ensino para o bom desempenho do professor em sala de aula. Versão On-line ISBN 978-85-8015-076-6, Cadernos PDE, 2013.

SILVA, Marilene Santos. Psicopedagogia: possibilidades de intervenção. In: MUSTACCHI, Z.; SALMONA, P.; MUSTACCHI, R. Trissomia 21 (síndrome de Down): nutrição, educação e saúde. São Paulo: Memnon, 2017, p. 227-244.

THOMPSON, James R. et al. Supports Intensit Scale. Washington, United States of America: American Association on Intellectual and Developmental Disabilities, 2004.

TRONCOSO, Maria Victoria; CERRO, Maria Mercedes del. Síndrome de Down: leitura e escrita um guia para pais, educadores e professores. Portugal: Porto, 2004.

VYGOTSKY, Lev Semyonovich. Pensamento e linguagem. São Paulo: Martins Fontes, 1987.

XAVIER, Odiva Silva; ARRUDA, Rosana Cezar Fernandes. A Aula em Espaços NãoConvencionais. In: VEIGA, IIma Passos Alencastro. Aula: Gênese, Dimensões, Princípios e Práticas. Campinas: Papirus Editora. 2008.

ZUTIÃO, Patrícia. Programa "Vida na Comunidade" para familiares de jovens com deficiência intelectual. 2016. 179 f. Dissertação (Mestre em Educação Especial) - Centro de Educação e Ciências Humanas, Universidade Federal de São Carlos, São Carlos, 2016. 
ZUTIÃO, Patrícia; BOUERI, Iasmin Zanchi; ALMEIDA, Maria Amelia. A avaliação das áreas adaptativas de jovens e adultos com Deficiência Intelectual. Educação, Batatais, v. 6, n. 3, p. 25-49, jul./dez. 2016.

\section{Correspondência}

Polyane Gabrielle de Freitas - Universidade Federal de São Carlos, Centro de Educação e Ciências Humanas, Departamento de Psicologia, Rodovia Washington Luís, Km 235, Jardim Guanabara, São Carlos, São Paulo - Brasil

CEP: $13565-905$

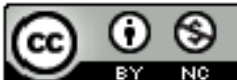

4.0 International (CC BY-NC 4.0) 